\title{
MyTF: A Joomla Template Design Package for Mobile Devices
}

\author{
Osunade $\mathrm{O}$. \\ Dept. of Computer Science of organization \\ University of Ibadan \\ Ibadan, Nigeria \\ o.osunade@ui.edu.ng
}

\author{
Ogwumike, J. O. \\ Dept. of Computer Science of organization \\ University of Ibadan \\ Ibadan, Nigeria \\ jedhppc@gmail.com
}

\begin{abstract}
Websites are created using programming languages such as HTML or content management systems (CMS). There are various technologies supporting the development of websites such as content management systems, JavaScript and ASP, thus numerous types of websites exist. Users access these websites through mobile devices and desktop systems. These users require access to websites that are easy to load, display content on small screens and have fast page loading speed. The existing web management systems are deficient in regards to meeting the needs of mobile device users. Thus, the aim of this project is to develop a template design package that will allow customized website access for mobile devices. The package utilized an existing web content management system platform called Joomla for the development while using the System Development Life Cycle (SDLC) approach. The tested package showed compatibility on mobile devices with positive results.
\end{abstract}

Keywords_Joomla; template design; mobile devices; website development; responsive design

\section{INTRODUCTION}

Websites are repositories of information structured in ways to promote actions profitable to an organization. The development of websites has been done using technologies targeted towards desktop systems. However, the rapid adoption of mobile technology and increasing processing capacity of mobile devices has generated new users and devices for accessing websites. The technological differences between the desktop systems and mobile devices are significant when accessing existing websites. These differences include varying browser software, screen sizes [9], mobility, limited power sources, network bandwidth, computational ability and many others. All these make the task of the web site administrators and content providers difficult in meeting the needs of mobile users.

Statistics obtained by [2] regarding user behaviour in terms of browsing the web and the prediction that "mobile Internet access will overtake fixed Internet access by 2014" indicated that web content should remain the same, while presentation should change depending on the context.

Developing a mobile version of an existing website requires a lot of effort in terms of time, workload and finance. The effort increases depending on the complexity of the website.
Hence, there is a need for websites which can be developed once and displayed effectively on both desktop systems and mobile devices. The aim of this work is to develop a website rendering package that will allow websites to be displayed on mobile devices without additional web design effort on the part of the website administrator or developer.

\section{LITERATURE REVIEW}

Content Management Systems (CMS) are developed to simplify content production and publishing for web developers and administrators. There are many CMS solutions e.g. Joomla, Drupal, OpenCMS, Plone, that are built to the open standard solutions that adopt the HTML5 version [1] and the CSS3 [3] version of mark-up and presentation language, respectively. CMS solutions allow the new features of HTML5 to be used to structure data embedded in the code. The Joomla Content Management System (CMS), allows creation and management of digital content, built on top of the Joomla platform. Joomla templates are used to change or customize the look of a website. According to [11] there are two types of templates used by the Joomla: Front-end Templates and Back-end Templates. The Front-end Template controls the way a website is presented to the user viewing the website's content. The Back-end template controls the way the website's administrative tasks such as template management, are presented to the Joomla Administrator. In this work the focus is on front-end templates for Joomla.

Website template design packages allow website layout rendering for mobile devices using style sheets based on device recognition. This technique is known as responsive design [4] Responsive design is based on specific features of CSS language and of HTML5 language: media queries and viewport $[4,5,6,7]$. Such techniques act on target device classes and inspect the physical features of devices. By using the media attribute of the HTML link tag, a developer can set the media types (screen, all, print, etc.) defining the screen dimension limits (e.g. max-device-width), or orientation (portrait/landscape). Such settings are then applied according to the devices recognized by the browsers and are then associated with one or more style sheets. 


\begin{tabular}{|c|c|c|c|c|}
\hline \multicolumn{5}{|c|}{ Table 1: Review of Popular Template design packages [8] } \\
\hline No & Package & Major Benefits & Limitations & Free/ Commercial \\
\hline 1 & JA T3 & $\begin{array}{l}\text {-Nice Design } \\
\text {-Comprehensive Features }\end{array}$ & $\begin{array}{l}\text {-Complicated Code } \\
\text {-Complicated Installation } \\
\text {-Code Editing Requirement for Layout } \\
\quad \text { Customization }\end{array}$ & Free, Commercial \\
\hline 2 & Gantry & $\begin{array}{l}\text {-Easy to use and customize. } \\
\text { - Very detailed documentation. }\end{array}$ & $\begin{array}{l}\text {-Moderate mobile support } \\
\text {-Social Media Integration lacking }\end{array}$ & Free, Commercial \\
\hline 3 & Warp & -Fast loading speed & -Social Media Integration lacking. & Commercial \\
\hline 4 & Gavern & $\begin{array}{l}\text {-Social media integration } \\
\text {-Fast loading speed. }\end{array}$ & -Limited available templates & Commercial \\
\hline 5 & Zen Grid & $\begin{array}{l}\text {-Nice Design } \\
\text {-Easy to use } \\
\text {-Rich features }\end{array}$ & -No mobile support & Commercial \\
\hline 6 & Helix & $\begin{array}{l}\text {-Easy to use. } \\
\text {-Fast loading speed. }\end{array}$ & $\begin{array}{l}\text {-No mobile support. } \\
\text {-Layout is not flexible. }\end{array}$ & Free, Commercial \\
\hline 7 & Construct & $\begin{array}{l}\text {-Averagely easy to use } \\
\text {-Fast loading speed }\end{array}$ & $\begin{array}{l}\text {-Limited mobile support } \\
\text {-No special features }\end{array}$ & Free, Commercial \\
\hline 8 & Morph & $\begin{array}{l}\text {-Keyboard shortcuts added } \\
\text {-Sophisticated features }\end{array}$ & \begin{tabular}{|l|}
-Complicated usage \\
-Slow loading speed \\
\end{tabular} & Free, Commercial \\
\hline 9 & JV & $\begin{array}{l}\text {-Drag and drop feature } \\
\text {-Built-in themes editor }\end{array}$ & -Limited mobile layout & Free, Commercial \\
\hline
\end{tabular}

Joomla Template design packages, also called website template processor [10] provide: easy customization; fast loading speed; social media integration; mobile support/responsiveness; drag and drop feature; and built-in theme editor. Table 1 shows a review of nine website template design packages.

According to [12], the activities involved in each stage of the template design package are stated below and shown in Figure 1:

- Problem Definition: involves formally stating the issues that the template design package intends to address. The major issue to be addressed by the template design package is the inability of important web page content to show up reasonably on a mobile device browser. This issue is also known as poor mobile support/responsiveness of a web page.

- Requirements Gathering: is the collation of specific requirements for the package design from the user and system perspectives. It helps to solve the problem identified in the problem definition stage.

- Requirements Analysis: involves three major tasks.

i. Determining system requirements: This task involves using the information provided by the requirements gathering stage to prepare the software requirements document for the template design package.

ii. Structuring system requirements by process modelling: graphically represents the processes, or actions, that capture, manipulate, store, and distribute data between the template design package and its environment and among components within the template design package. A common tool used for process modelling is Data Flow Diagram (DFD). iii. Structuring system requirements by conceptual data modelling: A conceptual data model of the template design package will be developed during this task. Entity Relationship Diagram (ER Diagram) will be used for the Conceptual Data Modelling of the template design package.

- Package Design: involves using the deliverables from the requirements analysis stage to design the rser interface and database of the template design package. Template design package settings are usually stored as XML and can be easily modified from the package's user interface. Settings in the template design package will also be stored as XML.

- Coding: The results of the earlier analysis is converted into programme code. Software tools used include Notepad++ text Editor, WAMP Apache Server for PHP, and relevant versions of the Joomla Platform.

- Unit Testing of the Package: Tests of the various components of the package during and after coding are done to ensure that they work according to specification.

- System Testing on the Joomla Platform: System testing involves running the template design package on the Joomla platform.

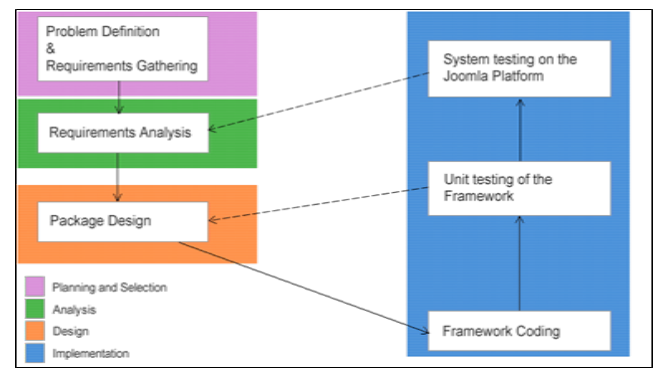

Figure 1: Process Model for the Package Development 


\section{Methodology}

This work used the Software Development Life Cycle (SDLC) approach to develop MyTF, a new template package to display Joomla websites on mobile devices.

Table 2 and 3 give the user, system, functional and nonfunctional requirements used to develop the Joomla Template design package.

Table 2: User \& System Requirements

\begin{tabular}{|l|l|l|}
\hline & \multicolumn{1}{|c|}{ User Requirements } & $\begin{array}{l}\text { System } \\
\text { Requirements }\end{array}$ \\
\hline $\begin{array}{l}\text { Web pages created } \\
\text { package must display } \\
\text { nicely on mobile web } \\
\text { browsers. }\end{array}$ & $\begin{array}{l}\text { The template design } \\
\text { package must be } \\
\text { compatible with Joomla } \\
\text { platform version 3.0 and } \\
\text { above. }\end{array}$ \\
\hline $\begin{array}{l}\text { Web pages should } \\
\text { fit different mobile } \\
\text { device screen sizes. }\end{array}$ & $\begin{array}{l}\text { Web pages created } \\
\text { using the package must } \\
\text { load fast. }\end{array}$ \\
\hline $\begin{array}{l}\text { Web pages should } \\
\text { load fast. }\end{array}$ & $\begin{array}{l}\text { Website layout } \\
\text { should be easy to modify } \\
\text { via a graphical user } \\
\text { interface. }\end{array}$ \\
\hline
\end{tabular}

Table 3: Functional/ Non-functional Requirements

\begin{tabular}{|l|l|l|}
\hline & $\begin{array}{l}\text { Functional } \\
\text { Requirements }\end{array}$ & $\begin{array}{l}\text { Non-functional } \\
\text { Requirements }\end{array}$ \\
\hline 1 & $\begin{array}{l}\text { The created web pages } \\
\text { must be mobile } \\
\text { compatible. }\end{array}$ & $\begin{array}{l}\text { The template should be } \\
\text { compatible with } \\
\text { Joomla 3.0 and above }\end{array}$ \\
\hline 2 & $\begin{array}{l}\text { Different screen sizes } \\
\text { must be supported by the } \\
\text { created web pages. }\end{array}$ & $\begin{array}{l}\text { Mobile compatible } \\
\text { CSS and HTML code } \\
\text { should be used. }\end{array}$ \\
\hline 3 & Web pages must load fast. & $\begin{array}{l}\text { The package should be } \\
\text { easily installable using } \\
\text { Joomla extension } \\
\text { manager. }\end{array}$ \\
\hline 4 & $\begin{array}{l}\text { Web pages should be easy } \\
\text { to modify. }\end{array}$ & $\begin{array}{l}\text { Relevant package } \\
\text { options should be } \\
\text { included in the } \\
\text { Template Details XML } \\
\text { file. }\end{array}$ \\
\cline { 3 - 4 } 5 & & $\begin{array}{l}\text { Package Option names } \\
\text { should be specified } \\
\text { explicitly in the } \\
\text { Template language } \\
\text { information file. }\end{array}$ \\
\hline
\end{tabular}

\section{MyTF, Joomla Template Design Package}

A Joomla template design package called MyTF was developed using PHP. MyTF was developed to use three modules to transform an existing website for display on a mobile device. Figure 2 shows the interactions between the modules.

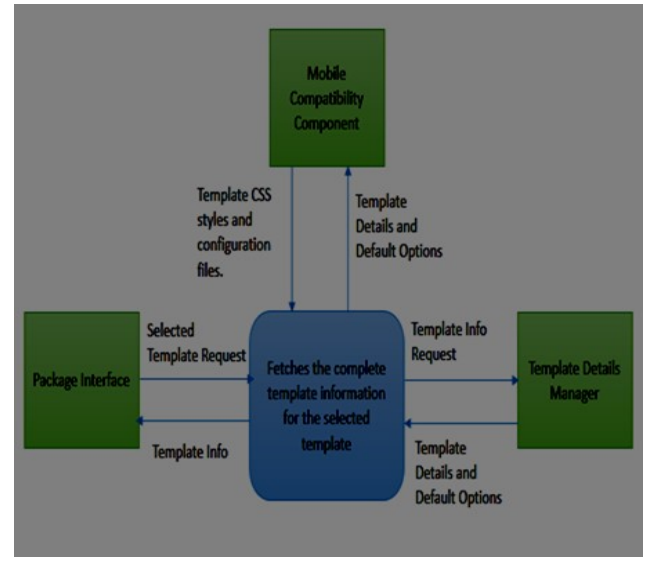

Figure 2: MyTF, Joomla Template Design Package

The functions of the three modules are as follows:

- Mobile Compatibility Component: This component includes the bootstrap.css code library which enforces mobile compatibility of all web pages created with this template design package.

- Package Interface: The function of this component is to send and receive data from the Joomla Platform. When a Template info request is received from the Joomla Platform, it is the duty of the template design package to fulfil that request by sending the relevant template information back to the Joomla Platform. The Joomla Platform can then use this information to arrange web page content for display on the device browser.

- Template Details Manager: This component fetches the template settings that have been prescribed in the templateDetails.xml file. These settings affect the positioning of web page content.

There are two major processes carried out within MyTF. The first process involves receiving the template request from the Package Interface and passing the request information to the Template Details Manager which initiates the request for mobile compatible CSS styles and configurations as well as default template module positions and option values. Once these requests have been fulfilled, they are combined to generate the complete template information which is then transferred to Joomla via the Package interface. The default settings for MyTF are stored as XML in a file named templateDetails.xml ensuring that the settings can be easily modified. 


\section{IMPLEMENTATION RESULTS}

MyTF was designed to be implemented using a web server (offline or online). The development and testing was done on a laptop with $2 \mathrm{~GB}$ RAM and $2.0 \mathrm{GHz}$ processor speed, while the following tools were used XAMPP Server Version 1.7, Joomla Platform Version 3.0, Adobe Dreamweaver CS5, Notepad++ Text Editor, and Web Browsers (Google Chrome, Mozilla Firefox, Internet Explorer, Opera) and PHP (Hypertext Preprocessor) Programming Language was used for coding.

The results of MyTF implementation are shown in the following screenshots.

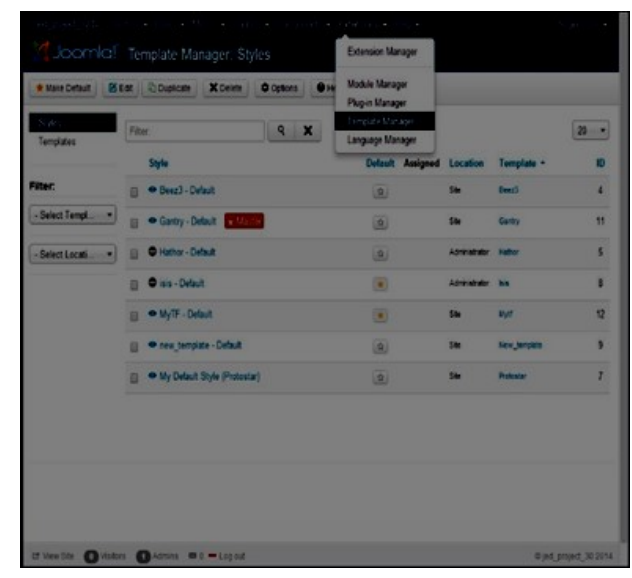

Figure 3: The Template Manager Page

The Template Manager page, shown in Figure 3, allows the installation and configuration of MyTF.

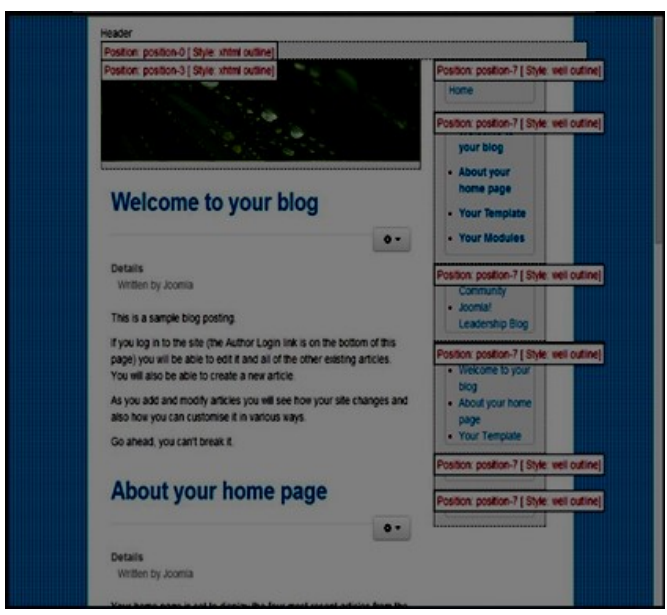

Figure 4: Template Module Positions

Figure 4 shows a screenshot of the module positions in a template as defined in the templateDetails.xml file. The sections where dynamic content from the Joomla database will be inserted are represented by these module positions (depicted in red text with prefix "Position: ")
The template design package when implemented on a desktop web browser, is as shown in Figure 5. It has a sidebar on the right, both the web page sidebar and the content at the top side towards the left of the sidebar are visible without scrolling down the page. However, Figures $6 \mathrm{a}$ and $6 \mathrm{~b}$ show the view on a mobile phone web browser. No sidebar is visible on the web page and the web page is displayed as a single column. The links which appeared on the sidebar of the desktop web browser now appear at the bottom of the web page on the mobile web browser.

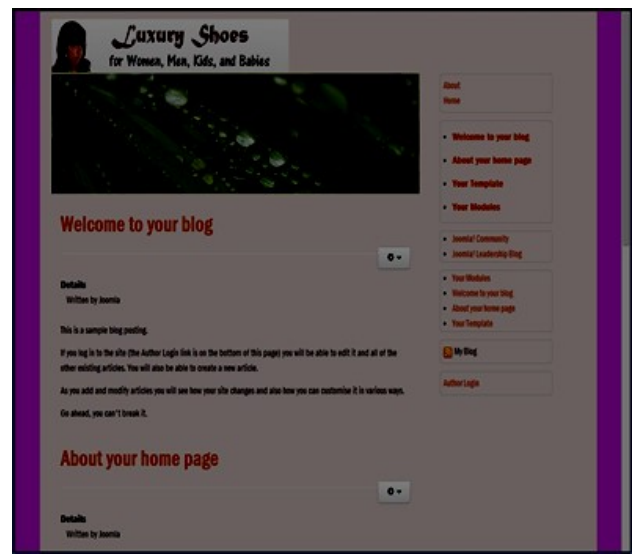

Figure 5: Website display on desktop system

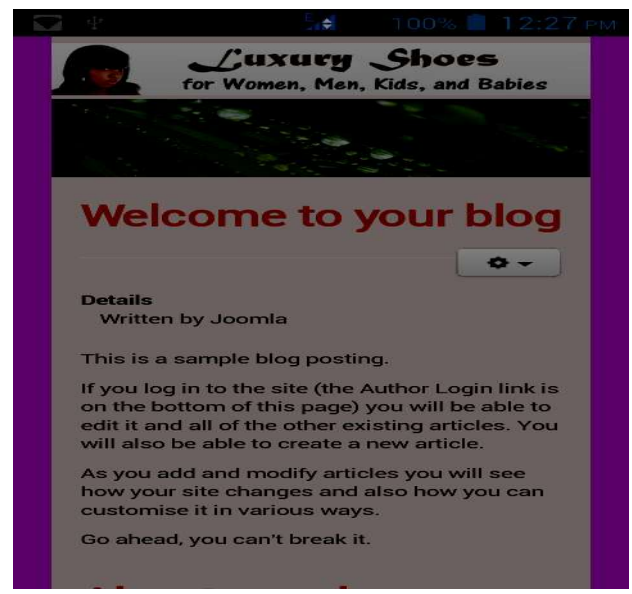

Figure 6a: Top screen of website on mobile device 


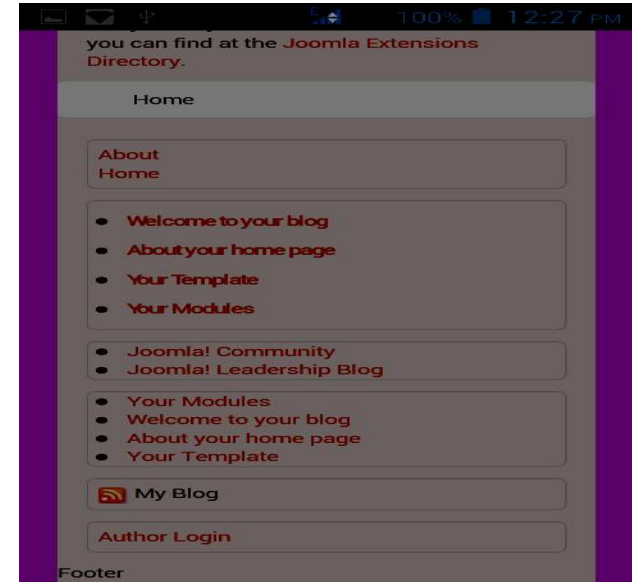

Figure $6 \mathrm{~b}$ : Bottom screen of website on mobile device

Table 4: Comparison of MyTF with ZenGrid

\begin{tabular}{|c|l|l|l|}
\hline & \multicolumn{1}{|c|}{ Requirements } & MyTF & ZenGrid \\
\hline 1. & $\begin{array}{l}\text { Display in mobile } \\
\text { web browsers }\end{array}$ & Yes & No \\
\hline 2. & $\begin{array}{l}\text { Display correctly on } \\
\text { different screen sizes }\end{array}$ & Yes & No \\
\hline 3. & Web page loads fast & Yes & Yes \\
\hline 4. & $\begin{array}{l}\text { Easy modification of } \\
\text { web layout }\end{array}$ & Yes & Yes \\
\hline 5. & $\begin{array}{l}\text { Compatibility with } \\
\text { Joomla 3.0 }\end{array}$ & Yes \\
\hline 6. & $\begin{array}{l}\text { Uses CSS and } \\
\text { HTML5 }\end{array}$ & Yes \\
\hline 7. & $\begin{array}{l}\text { Easy to install on } \\
\text { webserver }\end{array}$ & Yes & Yes \\
\hline 8. & $\begin{array}{l}\text { Package options } \\
\text { included in XML file }\end{array}$ & Yes & No \\
\hline
\end{tabular}

Table 4 shows the results of comparison of MyTF with ZenGrid, another Joomla template design package.

\section{CONCLUSION}

The developed template design package, MyTF, has the capacity to allow the rendering of any website developed on mobile devices. MyTF does the manipulation based on the user, system, functional and non-functional requirements. MyTF used a responsive design enforced by bootstrap CSS library to enforce mobile compatibility. Any website template can be used with MyTF to create a mobile device compatible website. The template design package developed during this project will improve the compatibility of website pages on mobile devices.

\section{REFERENCES}

[1] Pilgrim, M. 2010. HTML5: Up and Running, Published by O'Reilly Media Inc., ISBN: 978-0-596-80602-6.

[2] Murphy, M. and Meeker, M. 2011. Top mobile internet trends. Available http://www.charleswarner.us/kpcbtop10mobiletrends021011 finalpdf110210002130-phpapp02.pdf

[3] Gasston, P. 2011. The Book of CSS3: A developer's guide to the future of web design. Published by No Starch Press, ISBN-13: 978-1-59327286-9.

[4] Frain, B. 2012. Responsive web design with HTM15 and CSS3. Published by Packt Publishing Limited, ISBN 978-1-84969-318-9.

[5] Pastore, S. 2011. Distributed computing platforms like clouds and web standards: what could be the solution in an open environment? Proceedings of the WSEAS International Conference on Recent Research in Applied Computer and Applied Computational Science (ACACOS 2011), pp. 195-200.

[6] Fling, B. 2009. Mobile design and development: practical concepts and techniques for creating mobile sites and web apps. Published by O'Reilly Media Inc., ISBN: 978-0-596-15544-5.

[7] Appleseed, J. 2012. 8 Limitations when Designing for Mobile. Available at http://baymard.com/blog/mobile-design-limitations

[8] HuYennt. 2011. 9 Joomla Template frameworks for Web Developers. Available at http://www.joomlashine.com/web-development/9-joomlatemplate-framework-solutions-for-web-developers.html.

[9] Loza, C. 2011. The Disadvantages of Mobile Internet. Available at

[10] Niemeyer, P. 2002. Learning Java. Published by O'Reilly Media Inc., ISBN: 1565927184 .

[11] Joomla 2014. Templates. Available at https://docs.joomla.org/Templates

[12] Ogwumike, J. O. 2014. MyTF: A Joomla Template Design Package. Unpublished BSc project, University of Ibadan, 74pages. 